\title{
Studies on terrestrial interface processes in arid areas, China
}

(iP)

\author{
J.C. Li, D.L. Y ao \& W.M. Shen \\ Institute of M echanics, CAS, B eijing 100080, China
}

(Received 11 J une 1995, accepted 1 A ugust 1996)

\begin{abstract}
In the present paper, we have elucidated the importance of energy and water cycling in arid areas to investigate global climate and local economics. Then, we were concerned with the physical arguments as how to stratify the soil, and the stability of the numerical scheme in the mathematical model for predicting temperature variation and water motion. F urthermore, we discuss the methods to estimate evaporation in arid areas. N umerical simulation of energy and water cycling at the Acsu O bservatory, CAS, Xinjiang province and Shapuotou Observatory, CAS, N ingxia Province are conducted as case studies. The results show that the laws of terrestrial processes are rather typical in these arid areas. Planting drought-endurable trees can alleviate unfavourable conditions to a certain extent.
\end{abstract}

(C1997 Academic Press Limited

Keywords: terrestrial process; energy cycling; water motion; arid area

\section{Introduction}

Recently, people have paid much attention to the study of long-term weather forecasting, annual variation of climate and global warming. Since land occupies almost one-third of the earth surface, the terrestrial exchange process comprises an indispensable part of the climate system. In particular, the ecologically unstable arid and semi-arid areas tend to exert greater influences on climate due to desertification (Y ih et al., 1991). It is reported by UNEP that desertification occurs at the rate of approximately 6 million ha annually owing to world-scale climatic changes and overgrazing of land, which threatens the sustainable development of world economics. For example, dry weather led to accelerating advancing of the A takar D esert of South A merica at the speed of $1.6-3.2 \mathrm{~km}$ per year in 1960s. Hence, it is necessary for us to investigate energy and water cycling in typical areas of this kind. It should be noted that the laws of global and regional energy and water cycling are still not well understood. Current climate models are unable to delineate the processes of precipitation, evaporation and continental hydrology. For this reason, GEWEX and GCIP were included in WCRP in the middle of 1980s and planned to be carried out in 1990s, aimed at predicting global and regional hydrological processes, water resources and their environmental impacts so that these terrestrial processes can be incorporated into the climate models (Corell \& Anderson, 1990; Wood, 1991). 
On the other hand, the study of water and energy cycling is of vital importance for local economics development. F or instance, $\mathrm{X}$ injiang, as the largest province in $\mathrm{C}$ hina, is rich in mineral resources such as petroleum, gas and metals. Although local precipitation is low, there is sufficient water due to precipitation and melted snow in mountain areas. T he weather is fairly suitable for wheat, cotton, rice and fruit planting. However, although we have cultivated a large expanse of oasis, a great many environmental problems such as shrinking of rivers, drying of lakes, degeneration of pasture, desertification of land etc. occur (Wu, 1992). An additional example is the 'San Bei' windbreak to protect the railway from being buried by sand from the desert. A bout three decades ago, a few kinds of drought-enduring plants successfully survived by cellular straw technique at the south border of the T enggeli D esert. D uring the infant stage, they grew normally, thus resulting in the formation of a windbreak belt to hinder the movement of the desert. N evertheless, these plants started to wither due to the increased water demand and existence of a biological skin. $\mathrm{H}$ ence, understanding water movement in arid areas has become a challenging problem in order for these drought-enduring plants to survive (Zhao, 1991). Consequently, the study of energy and water cycling is certainly beneficial to the reasonable utilization of water resources, the balance of the ecological system, the improvement of environmental quality and the development of regional economics.

In 1991 and 1993, we made observations and measurements of water and energy cycling in typical arid areas with dry climates and strong insolation, at the Aksu Observatory, X injiang Province and the Shapuotou Observatory, N ingxia Province, CAS. T he present paper emphasizes the mathematical models, physical concepts and numerical results.

\section{Mathematical model for energy and water cycling}

H ere, we analyse temperature and moisture, two important hydrological parameters to influence sensible and latent heat transport, respectively, when discussing the energy and water exchange between land and atmosphere. To begin with, let's look at the multiple-scaled structure of temperature in the soil by examining the heat diffusion equation with external forcing:

$$
c \frac{\partial T}{\partial t}=\lambda \frac{\partial^{2} \mathrm{~T}}{\partial z^{2}}
$$

where $\mathrm{c}$ is the specific heat, $\lambda$ the heat conductivity, $\mathrm{T}$ the soil temperature, $\mathrm{t}$ the time and $z$ the vertical coordinate. As we know, there are various multiple-scaled phenomena in geophysical sciences such as diurnal, annual or longer-term variations. We assume that the external forcing temperature at the earth's surface is:

$$
T(0, t)=\bar{T}+\sum_{i=1}^{n} \Delta T_{i} \sin \left(\omega_{i} t+\phi_{i}\right)
$$

which means that the average temperature is superposed with varieties of periodic fluctuations. Then, the solution of Eqn (1) obeying boundary condition (2) looks like:

$$
T(x, t)=\bar{T}+\sum_{i=1}^{n} \Delta T_{i} \exp \left(-z / d_{i}\right) \sin \left(\omega_{i} t-z / d_{i}+\phi_{i}\right)
$$

where $d_{i}=\left(2 k / w_{i}\right)^{1 / 2}$ denotes the penetrating depth of heat, $k=\lambda / c$ the heat diffusivity, $w_{i}$ the circular frequency of the forcing temperature, $\phi_{i}$ the phase shifts and $T_{i}$ the amplitudes of fluctuation. We can see from Eqn (3) that the penetrating depth is 
proportional to the square root of periods and heat diffusivity, while the phase difference is proportional to the ratio of real depth to penetrating one.

Based on our previous analysis, we try to extend the so-called force-restore method proposed by Bhumralkar (1975) and Blackadar (1976). They divided the soil into three layers, namely, surface layer of thickness $\delta$, diurnal layer of depth $d_{1}(5-10 \mathrm{~cm})$ and annual layer of depth $d_{2}$ (1-2 $\mathrm{m}$ ) based on the heat diffusivity of soil being of the order $10^{-7} \mathrm{~m}^{2} \mathrm{~s}^{-1}$. T he temperatures of surface and deeper layer are assumed as $\mathrm{T} g$ and $\bar{T}$, respectively, to describe the thermal status of soil. D eardorff (1978) compared the results of the finite difference method and the modified force-restore method satisfactorily. Lin (1980) applied the method to the parameterization in climate modelling. T he present paper attempts to generalize the force-restore method to more general cases and derive the governing equations in the following:

$$
\begin{aligned}
\alpha \frac{d T_{g}}{d t} & =\frac{2 G(0, t)}{c d_{1}}-\frac{2 \pi}{\tau}\left(T_{g}-\bar{T}\right) \\
\frac{d \bar{T}}{d t} & =\frac{2 G(0, t)}{c d_{2}}
\end{aligned}
$$

where the surface temperature is defined as:

$$
T_{g}=\frac{1}{\delta} \int_{0}^{\delta} T(z, t) d z=(1-\varepsilon) T(0, t)+\varepsilon T(\delta, t)
$$

where $\tau$ is the diurnal period and $\alpha=1+2 \varepsilon \delta / d$, where $\varepsilon$ is a weighted factor. If $\varepsilon=1$ or $1 / 2$, they are consistent with Bhumralkar's model (1975) and Deardorff's model (1978), respectively.

Based on the conservation principles, we are able to derive water cycling equations by dividing soil into shallow and deep layer in a similar way. The governing equations look like:

$$
\begin{gathered}
\bar{d}_{1} \frac{d \theta_{1}}{d t}=\left(I_{b}-\frac{E_{b}}{\varrho_{w}}\right) \sigma_{b}+\left(I_{c}-U_{1}\right) \sigma_{c}-q_{12} \\
\bar{d} \frac{d \theta_{2}}{d t}=q_{12}-q_{23}-U_{2} \sigma_{c}
\end{gathered}
$$

where $\theta_{1}$ and $\theta_{2}$ are the moistures in the two layers with the depths $d_{1}$ and $d_{2}, E_{b}$ is the evapo-transpiration, $I_{b}$ and $I_{c}$ are the infiltration rates into bare or vegetated layers, $U_{1}$ and $U_{2}$ the water uptake rates through roots in layer 1 and $2, q_{12}$ and $q_{23}$ mean moisture fluxes through interface between layers 1 and 2 or 2 and 3 , and $\sigma_{b}$ and $\sigma_{c}$ denote the percentages of surface covered by bared soil or canopy. U nder irrigation condition, we still need to take subsurface runoff into consideration. The abovementioned physical quantities are calculated in the same way as in $\mathrm{Y}$ ao et al. (1992).

As for numerical method, we have chosen the Adams implicit difference scheme as the basis of multiple step algorithm, i.e.:

$$
\alpha_{q} Y_{n+q}+\ldots+\alpha_{0} Y_{n}=h\left(\beta_{q} f_{n+q}+\ldots+\beta_{0} f_{q}\right)
$$

with truncated error:

$$
R_{q}^{(2)}=h^{q+2} Y^{(q+2)}(\xi) \gamma_{q+1}
$$


where $h$ is the time step, $\gamma_{q+1}$ is a constant in the N ewton's interpolation obtained by the iteration formula:

$$
\gamma_{m}+\frac{1}{2} \gamma_{m-1} \ldots+\frac{1}{m-1} \gamma_{0}=1(m=0) \text { or } 0(m>0)
$$

For instance, if $q=1, R_{1}^{(2)}=-\frac{1}{12} h^{3} y^{(3)}(\xi)$. If the characteristic equations:

$$
\begin{aligned}
& \varrho(\xi)=\alpha_{x} \xi^{x}+\ldots+\alpha_{0} \\
& \sigma(\xi)=\beta_{x} \xi^{x}+\ldots+\beta_{0}
\end{aligned}
$$

are constructed in terms of the coefficients on both sides of Eqn (8), the scheme consistency requires $\varrho(1)=0, \varrho^{\prime}(1)=\sigma(1)$. In addition, the roots of $\rho(\xi)=0$ are assumed within the unit circle or on the circle of $|\xi|=1$ isolatedly. Then, the numerical scheme is stable due to consistency and convergence. Obviously, the following implicit scheme:

$$
Y_{n+1}-Y_{n}=h\left(f_{n+1}+f_{n}\right) / 2
$$

satisfies the foregoing conditions to assure the stability of the numerical algorithm. Eventually, with initial conditions and meteorological data given, we are able to predict water cycling and energy exchange in different ecosystems by numerical simulation.

\section{Evaporation estimation in arid areas}

Evaporation, as one of the crucial factors in the earth system, is the most important process linking energy and water cycling due to the need for latent heat in phase change. $M$ eanwhile, difficulties also come from being unable to measure it directly. $\mathrm{H}$ ence, scientists in the communities of geography, hydrology and agricultural sciences have paid much attention to the problem. T he study on evaporation can be traced back to the time of $D$ alton who first found out the influences of temperature, moisture and wind. The formulae to estimate evaporation can largely be divided into the following categories: the Bowen ratio method based on the balance of energy and the zero flux surface method based on the balance of mass. If we consider the exchange of water in the surface layer, then the aerodynamic resistance or vortex correlation method can be employed (Zuo et al., 1991).

Due to the complication and variance of evaporation on land, the concept of potential evaporation is proposed so that there is a standard with which to be compared. It is defined as 'the water loss in a large expanse of land covered by lower plants of the same kind with enough water supply'. Real evaporation may differ from potential evaporation due to various factors, for instance, the influence of edge (within

Table 1 Evapo-transporation coefficients for plants

\begin{tabular}{lcccccc}
\hline \multicolumn{5}{c}{ Growth periods } \\
Plants & initial & early & middle & late & harvest & Average \\
\hline Wheat & 0.35 & 0.75 & 1.13 & 0.70 & 0.23 & 0.85 \\
Cotton & 0.45 & 0.75 & 1.15 & 0.85 & 0.68 & 0.85 \\
Alfalfa & 0.35 & & & & 1.12 & 0.95 \\
\hline
\end{tabular}




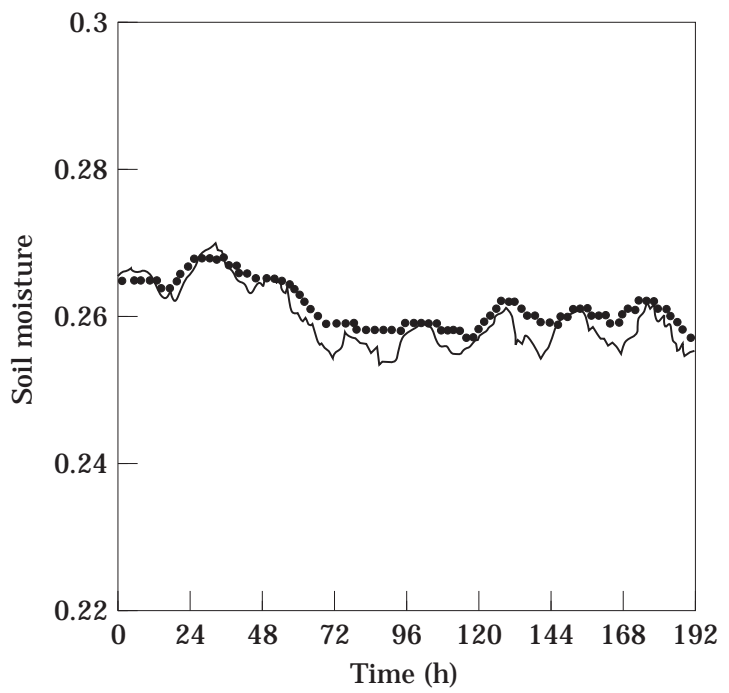

Figure 1 Variation of soil moisture at $10 \mathrm{~cm}$ depth with time. (---) numerical data; ( $\cdots$. observational data.

$20 \mathrm{~m}$ ), the species and height of plants (usually conifer evaporates less than deciduous trees), the period of growth (generally, coverage is larger during elongation and evaporate more in blossom and milk periods) etc. U sually, the potential evaporation can be estimated by potential evaporation at the water surface multiplied by evapotranspiration coefficients, namely:

$$
E_{m}=K_{c} E_{0}
$$

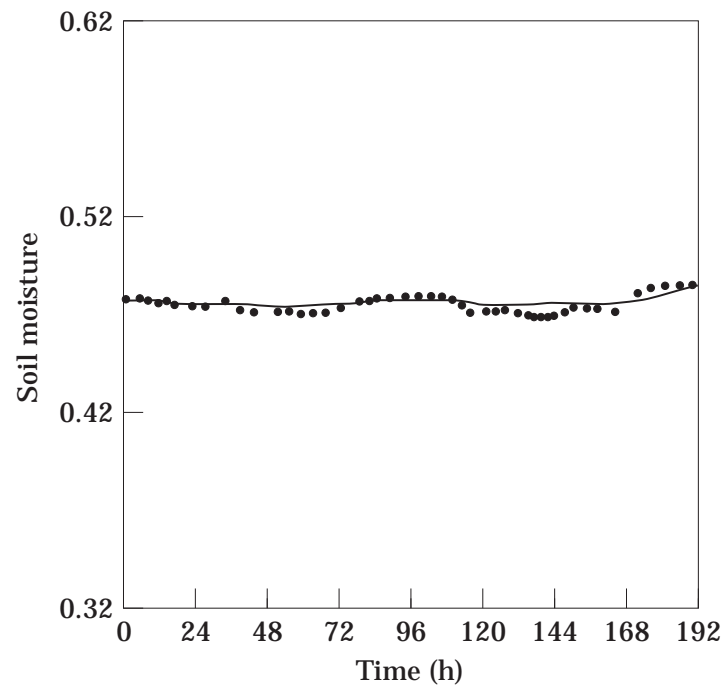

Figure 2. Variation of soil moisture at $100 \mathrm{~cm}$ depth with time. (---) numerical data; ( $\cdots$ ) observational data. 


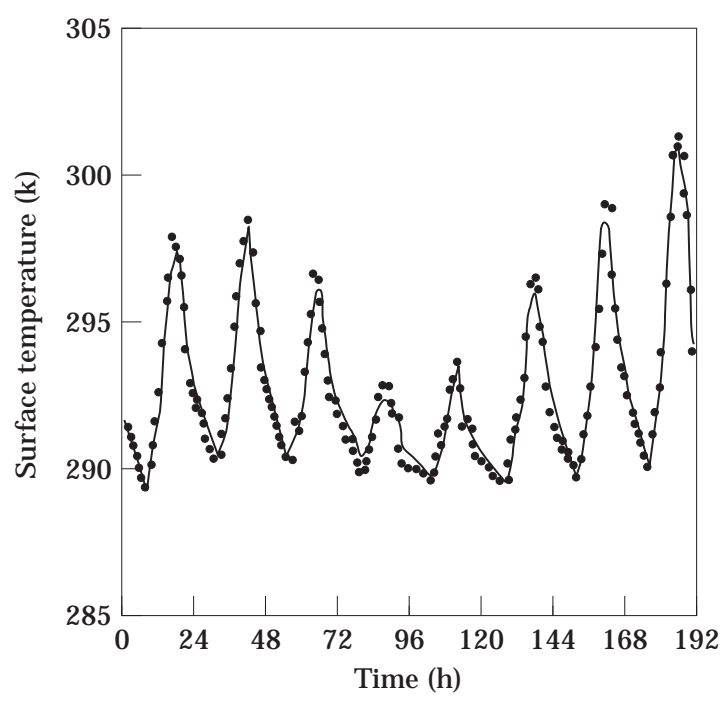

Figure 3. Variation of surface temperature with time. (---) numerical data; ( $\cdots$ ) observational data.

The latter is calculated according to the Penman formula:

$$
\mathrm{E}_{0}=\frac{\Delta \mathrm{R}_{\mathrm{n}}+\gamma \mathrm{E}_{\mathrm{a}}}{\Delta+\gamma}
$$

where $\Delta$ is saturated vapour pressure, $\gamma$ dry-wet constant, $R_{n}$ denotes net radiation and $E_{a}$ is the drying force for air. In contrast, the former is obtained by looking up in tables (see T able 1).

W ater is insufficient to supply plants growing in arid areas so that the evaporation is reduced correspondingly. As a matter of fact, this is one kind of physiological response

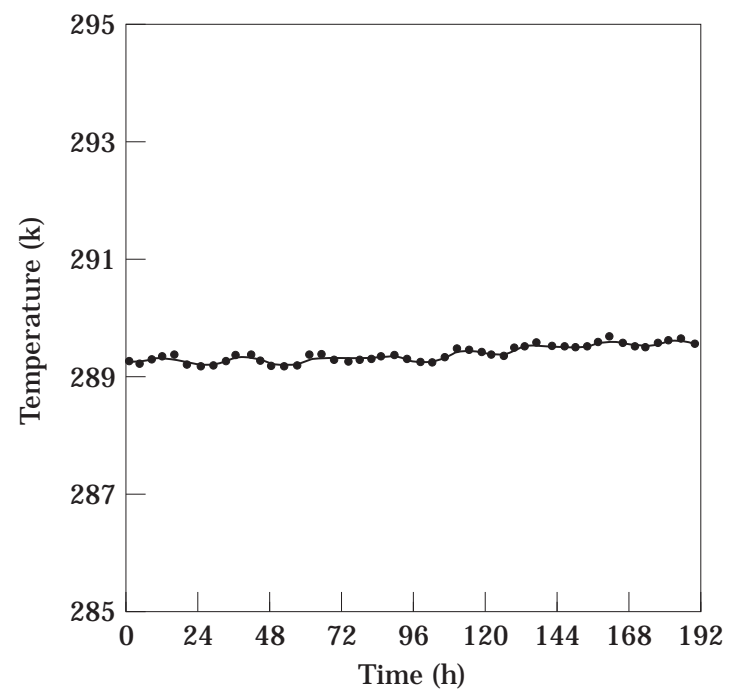

Figure 4. Variation of temperature at $100 \mathrm{~cm}$ depth with time. (---) numerical data; (...) observational data. 


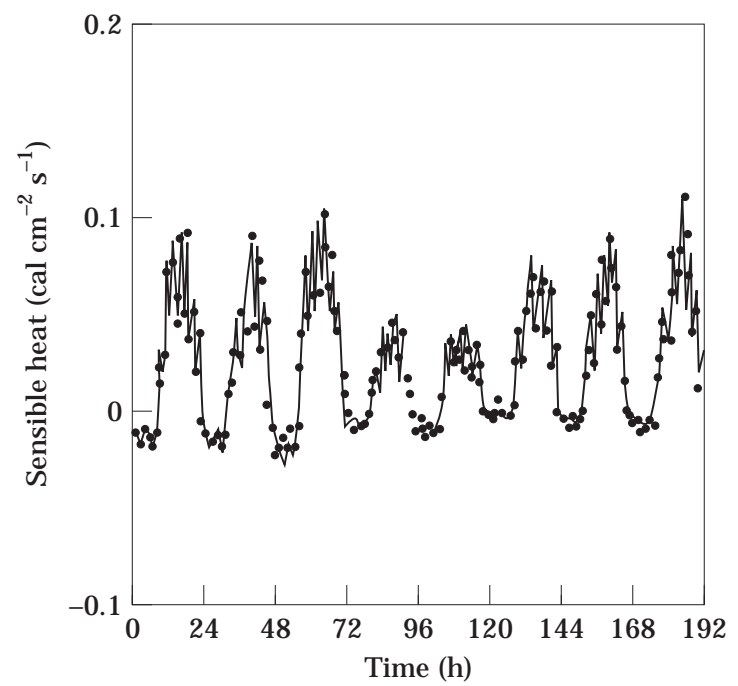

Figure 5. Variation of sensible heat with time. (---) numerical data; ( $\cdots$.) observational data.

to an unfavourable environment. Insufficient water supply leads to a lack of it in the body of the plant so as to close their stomata. The main task for us is to determine two parameters: the critical water capacity $\theta_{\mathrm{k}}$ (about $70-75 \%$ of field capacity) under which the evaporation is greatly reduced and the assimilation process almost stops; the water capacity for zero evaporation $\theta_{p}$ which is even lower than wither point since there is still little water made use of by plants. Then the real evaporation can be calculated according to the following expression:

$$
\mathrm{E}_{\mathrm{c}}=\left\{\begin{array}{cc}
\mathrm{K}_{\mathrm{cj}} \mathrm{E}_{0} & \theta \geq \theta_{\mathrm{k}} \\
\mathrm{K}_{\mathrm{cj}} \mathrm{E}_{0} \frac{\theta-\theta_{\mathrm{p}}}{\theta_{\mathrm{k}}-\theta_{\mathrm{p}}} & \theta_{\mathrm{k}}>\theta \geq \theta_{\mathrm{p}} \\
0 & \theta \mathrm{p}>\theta
\end{array}\right.
$$

where $K_{c}$ is the evapo-transpiration coefficients of plants, the suffix $j$ represent different growth periods. Thus, the evaporation in arid areas can be accurately estimated (Pei, 1989).

\section{Case studies}

\section{A ksu $O$ bservatory, $\mathrm{X}$ injiang province}

The numerical simulation of energy of water cycling at the A ksu O bservatory, $X$ injiang province is conducted by using the mathematical model mentioned above. T he Aksu Observatory is located at $40^{\circ} 30^{\prime} \mathrm{N}$ and $80^{\circ} 45^{\prime} \mathrm{E}$ with elevation $1028 \mathrm{~m}$ a.s.l. Temperature changes drastically from day to night or from summer to winter. The precipitation on average is $44.8 \mathrm{~mm}$ and wind speed $2.4 \mathrm{~m} \mathrm{~s}^{-1}$. So it is a typical temperate climate in inner land regions. The local soil consists of loam, in which saturation capacity is 0.389 , field capacity 0.25 and wither point 0.145 . The major vegetation is wheat, the LAI (leaf area index) of which is 3 during 14 to 21 June. The roughness of vegetation is $3.2 \mathrm{~cm}$, and the ratio of roots in the two layers is $0 \cdot 80: 0 \cdot 20$. 


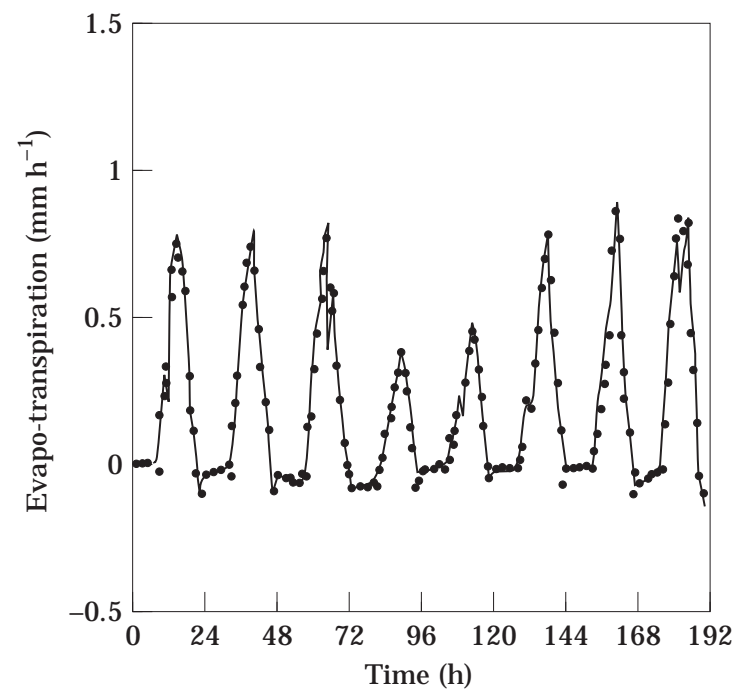

Figure 6. Variation of evapo-transpiration with time. (---) numerical data; ( $\cdots$...) computational data by Bowen ratio method.

Water motion is responsible for the variations of moisture contents in different layers. M oisture content in the shallow layer changes rapidly due to denser roots but also exhibits fluctuation of small amplitude due to periodic variation in evapotranspiration day and night. H owever, the moisture content in the deep layer hardly shows any variation due to rare roots (see Figs 1 and 2). The higher moisture in soil is due to irrigation in this area for agricultural development. The variations of temperatures at the surface and deeper layer as shown in Fig. 3, and Fig. 4 reflects the status of energy cycling. They are in good agreement with the measurements and confirm our prediction in diurnal and annual cycling, i.e. the surface temperature displays apparent diurnal rhythm and the temperature in the deep layer oscillates slightly and gradually increases with season. Figures 5 and 6 show the variations of sensible and latent heats with time, which seem to be consistent with the results by measurement and the Bowen Ratio method very well.

\section{Tenggeli D esert, Shapuotou O bservatory, N ingxia Province}

We have further applied the model to the arid area at the south end of the T enggeli D esert with only little vegetation coverage. Shapuotou located at $37^{\circ} 27^{\prime} \mathrm{N}$ and $104^{\circ} 57^{\prime}$ $\mathrm{E}$ belongs to semi-arid areas of the north-west inner land with a hot, dry and windy climate. The average temperature in this area is $9.6^{\circ} \mathrm{C}$ and the unevenly distributed precipitation, mainly in July to September, is $186.2 \mathrm{~mm}$ on average. Due to low relative humidity (usually $40 \%$, the lowest is 10\%, especially in Spring) and strong winds (averaging $5 \mathrm{~m} \mathrm{~s}^{-1}$ over 200 days), sand transport is very severe. There is little vegetation cover above $1-2 \%$ because the natural conditions are unfavourable for plants to grow owing to deep underground water and poor water-holding ability of sandy soil (usual water capacity is $2-3 \%$ ). To prevent the desert from moving southward, the Shapuotou Observatory have taken measures to fix flowing sand by combining mechanical and biological approaches. The former means to set up various kinds of sand barrier, while the latter is to plant appropriate bushes. H edisarum scoparium, Caragana korshinskii and A rtemisia ordosica seem to be the most effective trees. Due to larger roughness of the ground, wind and sand flow are considerably 


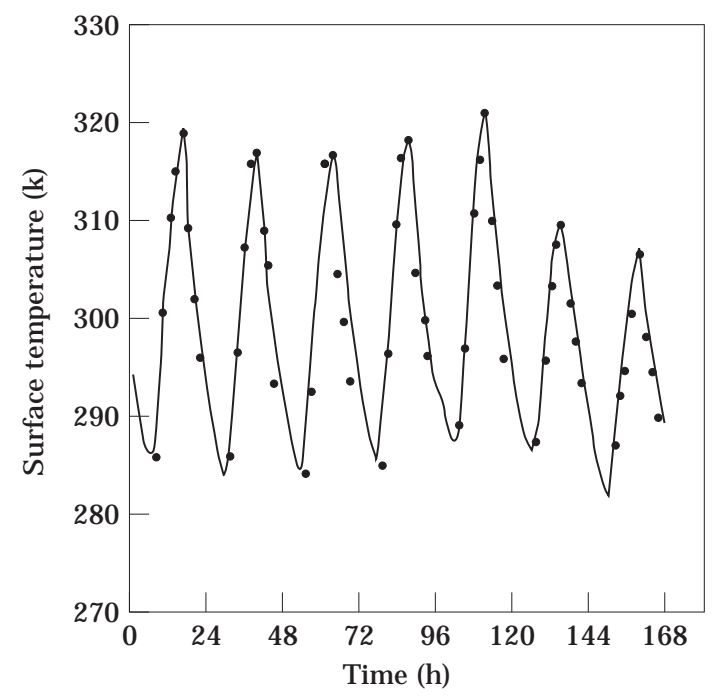

Figure 7. Variation of surface temperature with time. (---) numerical data; ( $\cdots$ ) observational data.

reduced. In addition, deposited fine sand and a large amount of fallen twigs or leaves leads to the formation of a soil skin by micro-organisms. It can enhance erosionresistant and water-holding abilities of sandy soil due to different physico-chemical behaviour. The skin is also beneficial to the growth of a plant with shallow roots.

The numerical simulation was conducted for the fields with bare soil or covered with Caragana korshinskii or Artimisia ordosica during 20-27 September. The soil is fine sand, containing little organic matter, calcium carbonate and nutrient. Its field capacity of water is $3 \cdot 34-3 \cdot 96 \%$ and wither capacity $0 \cdot 7 \%$. F igures $7-12$ show that the numerical results are in good agreement with observation. Figure 7 represents the temperature at the surface, exhibiting a tendency for more drastic diurnal variations

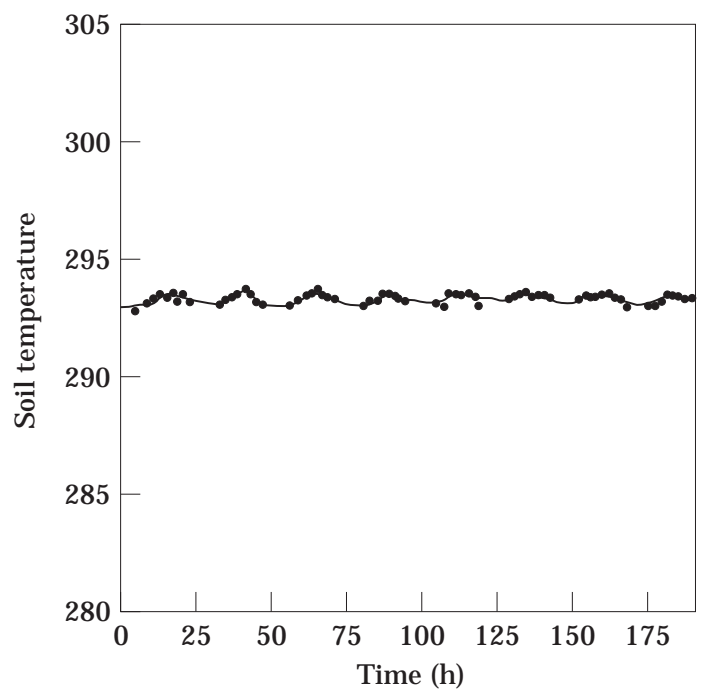

Figure 8. Variation of soil temperature at $120 \mathrm{~cm}$ depth with time. (---) numerical data; (...) observational data. 


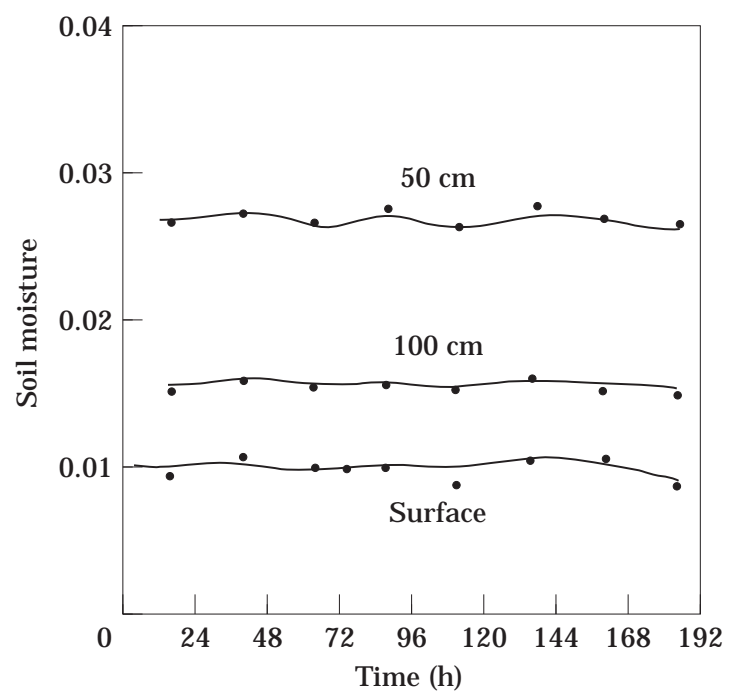

Figure 9. Variation of soil moisture at the surface, $50 \mathrm{~cm}$ depth and $120 \mathrm{~cm}$ depth with time. $(---)$ numerical data; $(\cdots)$ observational data.

than that of Acsu Observatory with a temperature difference of the order of $35^{\circ} \mathrm{C}$, while Fig. 8 shows the temperature in the deep layers with little variation. Figure 9 provides volumic capacity of water in the layers at the depths $10 \mathrm{~cm}, 50 \mathrm{~cm}$ and 120 $\mathrm{cm}$. A dry sand layer with moisture of only around $1 \%$ exists at the depth $6-7 \mathrm{~cm}$ so that the maximum of moisture content occurs at the depth $50 \mathrm{~cm}$ or so. The reason for the phenomenon is that dry climate in the area results in fierce evaporation and water cannot penetrate into the very deep layer or is even entirely evaporated if precipitation is less than $8 \mathrm{~mm}$, so that the most humid layer exists in the middle at the depth of 50 $\mathrm{cm}$ or so. We have also compared the evaporation rates for Caragana korshinskii, A rtemisia ordosica and bare soil. Caragana korshinskii has the largest LAI and leads to

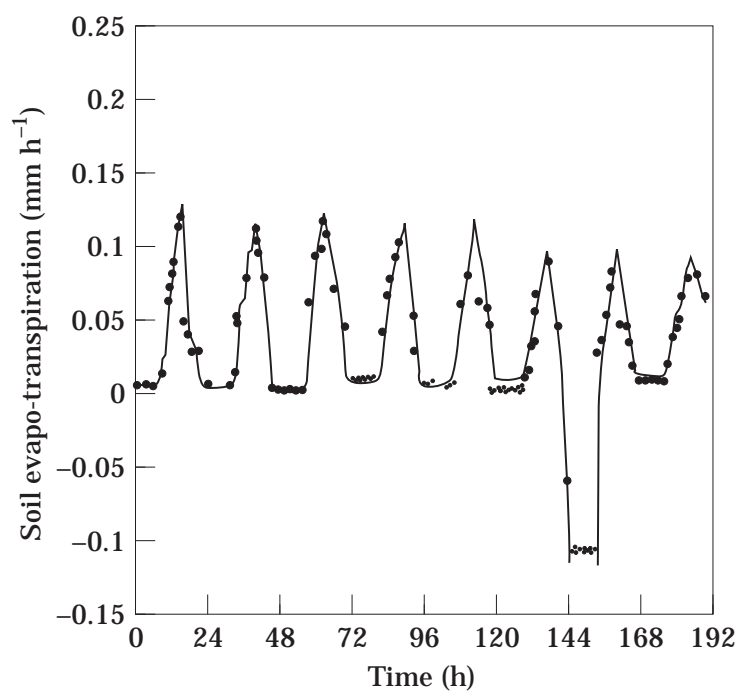

Figure 10. Variation of evapo-transpiration on bare soil with time. (---) numerical data; ( $\cdots .$. observational data. 


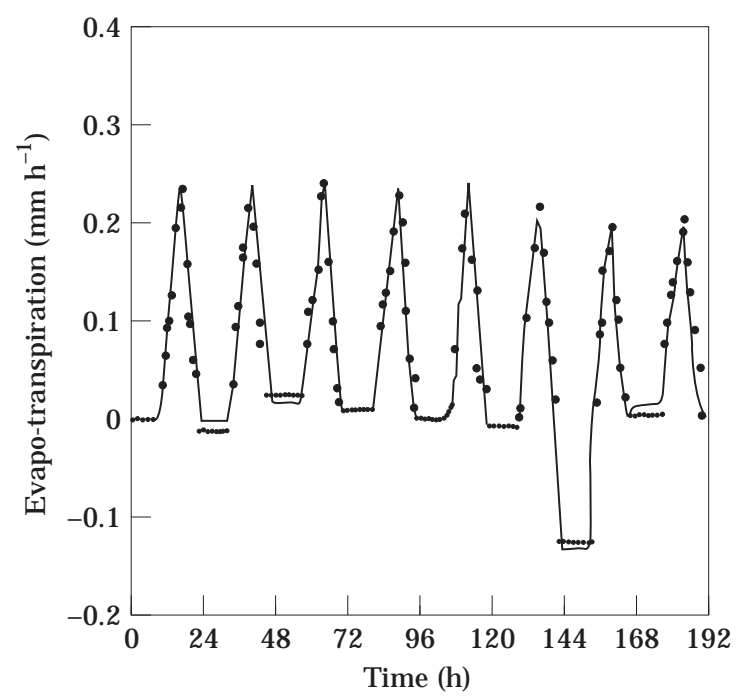

Figure 11. Variation of evapo-transpiration from Caragana korshinskii with time. (---) numerical data; $(\cdots)$ observational data.

the fastest evaporation rates. U sually, the maximum evaporation occurs around $1500 \mathrm{~h}$ local time and then reduces gradually to a minimum late in the night.

During observations for the two case studies, in addition to conventional weather observations for temperature, moisture by ASSM AN N ventilated psychrometer, wind speed by anemometer and pressure, we also measured radiation by $\mathrm{CN}-1$ net pyrradiometer, and evaporation by lysimeter. As for soil, the heat flux into the ground was measured by a $\mathrm{CN}-3$ thermal flux plate buried at a depth of $1 \mathrm{~cm}$. The water capacity was obtained by conventional baking and weighing method.

In summary, the mathematical model we have suggested can be used to simulate the energy and water cycling in arid areas so as to provide a scientific foundation to

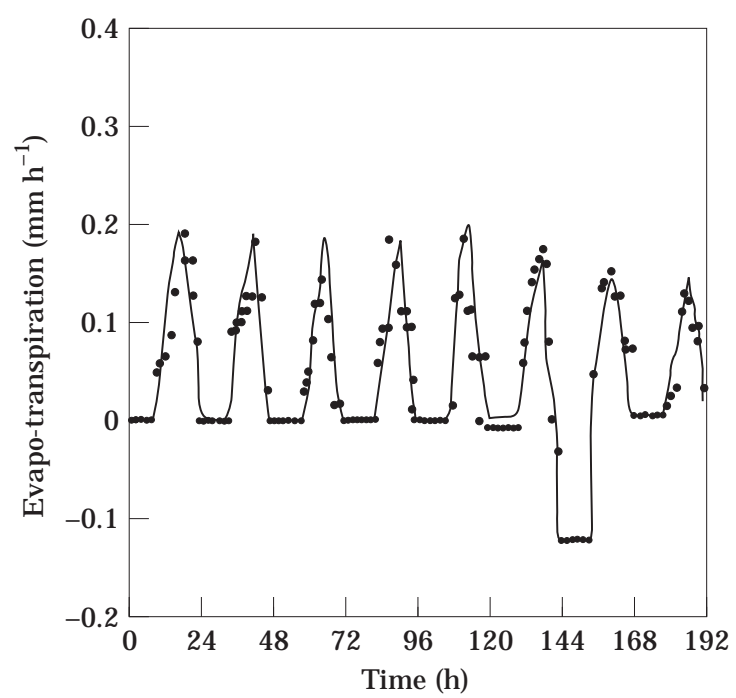

Figure 12 Variation of evapo-transpiration from A rtemisia ordosica. (---) numerical data; (...) observational data. 
develop industry and agriculture, plan local economics and investigate atmospheric sciences. Since the model studies the atmosphere and the soil separately, the consideration of the turbulent boundary layer, so as to develop a coupled model, is absolutely necessary.

The study is financially supported by LN M and LASG, CAS. T he authors are also grateful to the Acsu and Shapuotou Observatories for their cooperation and assistance.

\section{References}

Bhumralkar, C.M. (1975). Numerical simulation on the computation of ground surface temperature in an atmospheric circulation model. Journal of Applied M eteorology, 14: 1246-1258.

Blackadar, A.K. (1976). Modeling the nocturnal boundary layer. Proceedings of the 3rd Symposium on Atmospheric Turbulence, D iffusion and Air Quality, AM S, 46-49.

Corell, R.W. \& Anderson, P.A. (1990). G lobal Environmental Change, pp. 225-232. V1/N AT O, ASI Series. Berlin, Heidelberg: Springer-Verlag. 264 pp.

D eardorff, J.W. (1978). Parameterization of the planetary boundary layer for use in general circulation models. M onthly W eather R eview, 100. 93-106.

Lin, J.D. (1980). On the force-restore method for prediction of ground surface temperature. J ournal of G eophysical Research, 85, c(6): 3251-3254.

Pei, B.X. (1989). M easurement and Calculation of Evaporation and Evapotranspiration, pp. 82-144. Beijing: M eteorology Press. $210 \mathrm{pp}$.

Wood, E.F. (1991). Land surface-atmosphere Interaction for Climate M odelling, pp. 145-154. D ordrecht, The N etherlands: K luwer Academic Publishers. 314 pp.

Wu, S.Y. (1992). Studies on $H$ eat and M oisture Transfer in Tarim Basin, pp. 1-20, 84-113. Beijing: $M$ arine Publishing H ouse. 153 pp.

Yao, D.L. et al. (1992). N umerical simulation of water cycling and heat balance in agricultural ecosystems. A cta M ecanica Sinica, 2(8): 108-116.

Y ih, D.Z. et al. (1991). Research on C urrent Climates., pp. 236-261. Beijing: M eteorology Press. $353 \mathrm{pp}$.

Zhao, X.L. (1991). H arness of D rifting Sand, pp. 1-58. Yinchaun: N ingxia People's Publishing H ouse.

Zuo, D.K. et al. (1991). Advances in the study of evaporation abroad. In: Xie, X.Q. et al. (Eds), Field Evaporation, pp. 14-21. Beijing: M eteorology Press. 237 pp. 